\title{
Unconventional Gas Production from Hydraulically Fractured Well-An Application of Direct Search Based Optimization Algorithm
}

\author{
M.M. Rahman, A. Suboyin, M. Haroun
}

\begin{abstract}
Unconventional gas reservoirs are now the targets for meeting the demand for gas. These reservoirs are at the depth of more than 10,000 ft (even over 15000 depth as well) and are difficult to be exploited by conventional methods. For the last decades hydraulic fracturing has become the tool to develop these resources. Mathematical models (2D and pseudo-3D) have been developed for fracture geometry, which should be realistically created at the depth by surface controllable treatment parameters. If the reservoir rock is sandstone, then proppant fracturing is suitable and if the rock is carbonates, then acid fracturing is applicable. In both cases, proper design of controllable treatment parameters within constraints is essential. This needs proper optimization model which gives real controllable parametric vales. The model needs the most important analyses from geomechanical study and linear elastic fracture mechanics of rock containing unconventional gas so that fracture geometry makes maximum contact with the reservoirs for maximum recovery. Currently available software may lack proper optimization scheme containing geomechanical stress model, fracture geometry, natural fracture interactions, real field constraints and proper reservoir engineering model of unconventional gas resources, that is, production model from hydraulically fractured well (vertical and horizontal).
\end{abstract}

An optimization algorithm has been developed to integrate all the modules, as mentioned above, controllable parameters, field constraints and production model with an objective function of maximum production (with or without minimization of treatment cost). Optimization is basically developed based on Direct Search Genetic and Polytope algorithm, which can handle dual objective function, non-differentiable equations, discontinuity and non-linearity. A dual objective function will meet operator's economic requirements and investigate conflict between two objectives. The integrated model can be applied to a vertical or horizontal well in tight gas or ultra-tight shale gas deeper than over 10,000 ft. A simulation (with industrial simulators) was conducted to investigate and analyse fracture propagation behavior, under varying parameters with respect to the fracture design process, for tight gas reservoirs. Results indicate that hydraulic fracture propagation behavior is not uninhibited in deep reservoirs as some may believe that minor variations of variables such as in-situ stress, fluid properties etc. are often detrimental to fracture propagation in some conditions. Application of this model to a hypothetical tight and ultra-tight unconventional gas formations indicates a significant gas production at lower treatment cost; whereas the resources do not flow without any

Revised Version Manuscript Received on 10 September, 2019.

M.M. Rahman, Khalifa University of Science and Technology, Abu Dhabi, UAE

A. Suboyin, Khalifa University of Science and Technology, Abu Dhabi, UAE.

M. Haroun, Khalifa University of Science and Technology, Abu Dhabi, stimulation (hydraulic fracturing).

\section{INTRODUCTION}

Application of geomechanics to create a fracture hydraulically in a rock formation deeper than $10,000 \mathrm{ft}$ from the surface onshore and offshore to exploit more oil and gas has been practiced over decades. This has become applied engineering of hydraulic fracturing in the petroleum industry to produce conventional and unconventional hydrocarbon resources. To design this fracture, a certain operational parameters are required, which are functions of geomechanics, hydrocarbon properties and surface operational constraints. Of course, economics and environmental issues are highly important in the industry. The operational parameters are to be designed as an optimal ranges of values for treatment (design) parameters, such as fracturing fluid viscosity (power law parameters), injection rate \& time, proppant concentration, etc, so that a desired fracture geometry can be created to achieve the objectives in a given deeper rock formation [1-4]. This becomes a complex problem which must be combined with formation in-situ properties, hydraulic fracture growth based on volume balance of injected fracturing fluid, reservoir fluid flow through fractures and economics. Design should be optimized satisfying all controlled and uncontrolled realistic requirements, so that the operational parameters are executable while fracturing. Various methods are available in the literature to perform each of these tasks in the overall solution process. The solution method adopted over decades is not well established [1-4].

Several solution methods have been developed, but some perform a particular task on a number of assumptions, which apply to a particular formation. Selection of an inappropriate method may cause unnecessary mathematical complexity with no better solution than any arbitrary design. This does not achieve the objectives globally. To systematically deal with such complexities/uncertainties at various levels, the authors presented this work as a hydraulic fracturing design process for unconventional gas resources. An globally appropriate method to perform a task is selected based on various aspects of the job, the degree of sophistication required in modeling the overall problem and uncertainties involved with all the alternative methods $[1,2,4]$. In selecting a method for a particular node, a bi-directional information exchange with compatible accuracy levels is emphasized between the decision node and its connecting nodes in a 


\section{UNCONVENTIONAL GAS PRODUCTION FROM HYDRAULICALLY FRACTURED WELL-AN APPLICATION OF DIRECT SEARCH BASED OPTIMIZATION ALGORITHM}

system analysis approach. The solution tool is seldom considered as an integral part of the overall hydraulic fracturing design process for exploiting unconventional gas resources [1-4].

This work selects a mathematical solution technique and then selects one for hydraulic fracture design task assessing must be reflected in all other decision nodes. That is, solution technique should be able to handle certain features of the overall problem (e.g. non-linearity, discontinuity, non-differentiability), then the overly sophisticated modeling does provide a good design. The overall modeling process is developed in a framework of an algorithm for optimum solution $[1,4,5]$.

Even after stimulation of such formations, the targeted permeability and production is often not achieved in ultra-tight formations. Authors study the complication of flow behavior of hydrocarbons and other fluids in reservoirs due to natural fractures that exist within such reservoirs. This leads to complexities such as premature water breakthroughs, reduced recovery rates, channeling of injected fluids, fracture collapses as conduits due to changes in reservoir pressure [6]. These ultimately lead to higher expenditures along with ultimate recoveries that are lower than expected, particularly development of shale reservoirs is still associated with a high degree of uncertainty and risk. As a significant amount of time, money, material and manpower is involved, it is crucial to optimize the design while achieving the target. Further studies indicate that for an effective, efficient and economical hydraulic fracture treatment design the impact of various in-situ parameters along with the design parameters must be analyzed in depth to better understand the fracture propagation behavior [6-9].

In this paper authors emphasized the need of optimum and goal-oriented design (with the significance of contributing parameters to the fracture geometry and post-fracture fluid flow) and also discussed the benefits of hydraulic fracturing, without which tight and ultra-tight gas formations cannot be exploited.

\section{DIRECT SEARCH BASED ALGORITHM}

The overall hydraulic fracturing design is an integrated model of a system analysis (Figure 1). Optimization algorithm is a solution tool and a module in the integrated model. This algorithm is genetic and polytope and is described briefly here, which is based on direct search method. The fundamental of mathematical programming is usually formulated as the optimization (either maximization or minimization) of a function $\mathrm{f}\left(x_{1}, x_{2}, \ldots \ldots, x_{\mathrm{N}}\right)$ of several variables $x_{1}, x_{2}, \ldots ., x_{\mathrm{N}}$ subject to the satisfaction of design constraints $[1,5,10]$.

There are many developments on optimization methods and their applications to linear and nonlinear problems [11,12]. Mathematical programming methods are the classical techniques of optimization as applied to nonlinear programming. Most methods were invented by mathematicians based on classical differential calculus, and they inherit the assumptions of differentiability, gradient vectors and second derivatives. With respect to problems with smooth functions that are differentiable, the mentioned derivative based methods are often regarded as reliable while its special features. The capability of the solution technique

being computationally efficient. However, in reality, multiple engineering design problems in the real-world often involve discontinuous and non-differentiable functions, design variables that require a combination of continuous, integer and discrete values along with conflicting multiple design objectives. By implementing various numerical differentiation techniques with various degrees of accuracy, the complexity of non-differentiability in using the methods is overcome $[1,10]$. Attentions have been focused to develop alternative algorithms, particularly direct search methods, by manipulating fundamental mathematics of optimization methods. They are normal-boundary intersection algorithm [13], genetic algorithms (GA) [14], polytope algorithm (PA) [15], and evolutionary operation (EVOP) [10]. Direct search methods, which are GA, PA and EVOP, are generally slow in convergence but are successful in finding reliable optimum solutions of problems having high degree of discontinuity and non-differentiability in functions $[1,10]$.

The objective and constraint functions consist of all mathematical equations involved in hydraulic fracturing and post-fracture gas production. These equations are highly non-linear and non-differentiable. Hence, these are exposed to a certain number of discontinuities which include numerically unstable sub-functions (the complementary error function and bi-section solution). Direct search based algorithm, combining the major features of GA and PA finds optimum solution by generating and moving an object (called 'compound') using 'intelligence' more than mathematics $[1,10]$.

General formulations of this algorithm can be stated as $[3,5,10]$ :

Find

$$
\underline{x}^{\mathrm{T}}=\left\{x_{1}, x_{2}, ., x_{i}, \ldots, x_{N}\right\}
$$

Which is subjected to bound constraints represented as

$$
\left.\begin{array}{c}
l_{1} \leq x_{1} \leq u_{1} \\
\cdot \cdot \\
\cdot \cdot \cdot \cdot \\
l_{N} \leq x_{N} \leq u_{N}
\end{array}\right\}
$$

and design constraints represented as

$$
\begin{aligned}
& C_{l 1} \leq C_{1}(\underline{x}) \leq C_{u 1} \\
& \left.\begin{array}{cc}
\cdot & \cdot \\
C_{l M} \leq C_{M}(\underline{x}) \leq C_{u M}
\end{array}\right\}
\end{aligned}
$$

to ultimately minimize

$$
Z=f(\underline{x})
$$

where,

$\underline{x}$ denotes the vector of free design variables (the superscript ' $\mathrm{T}$ ' for transpose); $l_{i}$ 's and $u_{i}$ 's are constants or functions of $\underline{x}$ (in the latter case the bound constraints constitute moving boundaries) representing the ranges of $x_{i}$ 's; 
$C_{l i}$ 's and $C_{u i}$ 's are constants or functions of $\underline{x}$ representing the acceptable ranges of design constraints, $C_{i}(\underline{x})_{\text {'s; }}$;

$N$ is the total number of free design variables; and $M$ is the total number of design constraints.

The function $f(\underline{x})$ is to be minimized, which can be regarded as a single objective or multiple objectives $[3,5,10]$.

The optimisation procedure begins with an initial point (vertex) in the $\mathrm{N}$-dimensional space, which are constrained by the design variables range, as shown in Figure 2, within a two-dimensional space. Straight lines $\left(l_{1}, u_{1}\right.$ and $\left.l_{2}, u_{2}\right)$ that are parallel to the co-ordinate axes represent the lower and upper bounds on variables, $x_{1}$ and $x_{2}$, respectively. Curved lines $C_{l l}$ and $C_{u l}$ represents the lower and upper bounds, respectively, on design constraint $1, C_{1}(\underline{x})$, and $C_{l 2}$ and $C_{u 2}$ on design constraint $2, C_{2}(\underline{x})$. Certainly, there could be more than these two design constraints and their lower and upper bounds. The area along the hatched direction is the two-dimensional feasible search space. The initial vertex (arbitrary design) must be within the variable bounds, and may or may not satisfy the design constraints. If the initial vertex does not satisfy any of the design constraints (i.e. not within the hatched area), a random vertex is generated $[1,5,10]$. If the random vertex is still within the region considered infeasible, the distance between these two vertices is estimated and the generated vertex is moved stepwise halftimes the distance each time along the straight line with these two vertices until all the design constraints are met by the vertex. A negative step-length is used, if the positive step-length moves the vertex away from the unsatisfied design constraint bound(s). The vertex ' $a$ ' is either an initial feasible vertex, or a vertex moved from its initial infeasible location $[1,10]$. The coordinates of a random vertex are generated by:

$$
x_{i}=l_{i}+r_{i}\left(u_{i}-l_{i}\right) ; \quad i=1, \ldots \ldots \ldots, N
$$

The pseudo-random deviate $r_{i}$ rectangularly distributes over the interval $(0,1)$ and is controlled by the known value, $x_{\text {in }}$ for the $i$-th coordinate of the initial vertex $[5,10]$.

Executing Eq. $5 K$-1 times, further $K$-1 different random points are generated, where $K=2 N$ for $N \leq 5$ and $K=N+1$ for $N>5$. Eq. 5 ensures that the randomly generated points remain within the space bounded by ranges of variables that are defined previously by Eq. 2. Since any of the generated points may violate any of the design constraints defined by Eq. 3, and therefore a technique is required to move such points towards satisfying Eq. 3. The four vertices for two-dimensional space a, b', c' and d' are shown (Figure 2) $[1,5,10]$. Obviously, vertices $b^{\prime}, c^{\prime}$ and d' violate Eq. 3 . These vertices are modified in the order of $d^{\prime}, c^{\prime}$ and $b^{\prime}$ by moving successively towards the centriod, $\underline{c}$ by:

$$
\underline{x}=\frac{1}{2}\left(\underline{c}+\underline{x^{\prime}}\right)
$$

until the new point, $\underline{x}$ satisfies Eq. 3 . The coordinates of the cenrtriod, $\underline{c}$ are calculated using vertices that have already satisfied Eq. 3 as follows:

$$
c_{i}=\frac{1}{n} \sum_{i=1}^{n} x_{i}
$$

where $n$ is the number of vertices which have already satisfied Eq. 3.

The modified feasible points are a, b, c and d which satisfy both Eqs. 2 and 3. These four feasible vertices comprise an object called 'compound' abcd (Figure 2). The values of the objective function, $f(\mathrm{a}), f(\mathrm{~b}), f(\mathrm{c})$ and $f(\mathrm{~d})$ at these four vertices are calculated and assumed to be in the order of $f(\mathrm{a})<f(\mathrm{~b})<f(\mathrm{c})<f(\mathrm{~d})$. If the initial notations of vertices do not satisfy this order, vertices are re-denoted according to this order. In fact, the point that corresponds to the minimum objective function value is preserved and the new random points are generated around this point $[1,6]$. The procedure is repeated as long as objective function can be minimized further. In a sense, the same point (object) is moving to a new location in every step, using intelligent information until the minimum objective function is established $[1,4,10]$.

The above method for moving an infeasible vertex to the feasible space would be successful without any doubt in generating a compound with $K$ vertices, for a convex feasible parameter space. If the parameter space is nonconvex, and the centroid happens to lie in the infeasible area, there is every chance that a compound cannot be generated. Figure 3 shows such a possibility. Three vertices $\mathrm{a}, \mathrm{b}$ and $\mathrm{c}$ in the feasible parameter space have already been generated [4]. In order to generate the fourth feasible vertex a trial point, $\mathrm{T}_{1}$ satisfying the variable bounds is created. However, $\mathrm{T}_{1}$ is infeasible as it violates a design constraint. In order to make $T_{1}$ feasible it is continually moved halfway towards the centroid, $x$. Since the centroid itself is infeasible no amount of such moves would make $T_{1}$ feasible, and a compound with four vertices can never be generated. Safeguard against such a possibility is never to allow an infeasible centroid. If a new feasible vertex results in the new centroid to lie in the infeasible area, that new vertex is discarded, and another generated until a feasible centroid is obtained $[4,5,10]$.

\section{MECHANICS OF HYDRAULIC FRACTURE}

Hydraulic fracture is derived from science of rock mechanics. In petroleum engineering, fracture shape is defined by length, height and width of a fracture, which are function of fracture treatment parameters. Finally, propped fracture geometry helps reservoir fluid flow towards the wellbore. Figure 4 shows a $2 \mathrm{D}-\mathrm{PKN}-\mathrm{C}$ fracture model utilized in this work, because its vertical plane strain assumption is physically more acceptable for the proposed height-contained fracture where the fracture length becomes considerably greater than the fracture height $[16,17,18]$. The model can incorporate properties of both Newtonian and non-Newtonian fracturing fluids. For detail of the model's mathematical equations, readers are advised to see the reference of Valko and Economides [8].

A pseudo-3D model for multi-layered formations is also proposed, derived originally from $2 \mathrm{D}$ model. The $3 \mathrm{D}$ models are usually called 'pseudo' and is being utilized by the 


\section{UNCONVENTIONAL GAS PRODUCTION FROM HYDRAULICALLY FRACTURED WELL-AN APPLICATION OF DIRECT SEARCH BASED OPTIMIZATION ALGORITHM}

industry for fracturing design. Models do not consider the variation of fracture geometry in a $3 \mathrm{D}$ space, rather it is the modified version of 2D-PKN-C model with height declining along the fracture length. There is a variation of fracture width along the fracture length $\left(x_{\mathrm{f}}\right)$ and height. The fracture height variation along the fracture length is considered linear or parabolic $[19,20]$. The equilibrium height variation of a fracture for a given wellbore bottomhole and internal pressure in a three-layer-stress environment can be calculated if material property in each stress layer and vertical pressure distribution in the fracture are assumed constant. However, Poisson's Ratio in each layer are considered different. The stress-intensity factors are calculated at the top and bottom tips of the fracture and set equal to the fracture toughnesses of the materials, resulting in a unique height and position, or centering of the crack with respect to the stress field $[19,20]$. Readers are advised to see the reference of Warpinski and Smith [20] for details of mathematics.

\section{FLUID FLOW FROM HYDRAULICALLY FRACTURED WELL}

For unconventional formations, particularly moderate and tight formations, several models are developed; but for ultra-tight (with nano-Darcy) formation, model is not well defined because Darcy equation is not enough to model the gas flow. There is tri-linear fluid flow model developed for transversely fractured horizontal well, however, this needs to be further refined [21] for a hydraulically fractured horizontal well; however, it is not suitable for nano-Darcy formations. For ultra-tight and unconventional gas resources a fluid flow model based on compartmentalized reservoir engineering is desirable and is still under development. In fact, this is a complex inter-relationships between matrix, natural fracture, propped hydraulic fracture, wellbore and fluid and geomechanical properties, a predictive model needs to be developed or being developed in the industry with all realistic constraints. A few software are being used by the industry to predict the gas production from unconventional formations fractured hydraulically. For details of mathematical model, readers are advised to read the literatures [22-25].

\section{TREATMENT PARAMETERS AND DESIGN REQUIREMENTS}

There are free design variables, which are called hydraulic fracturing treatment parameters. They are injection rate, injection time, fracturing fluid viscosity (with power law parameters) and proppant concentration and are directly or indirectly related to fracture geometry and gas flow from fractured well. Fracture half-length, height and width are computed as function of these variables by solving the coupled-material balance relationship. Each free design variable has an upper bound and a lower bound value, based on field practices (Table 1). Some important design requirements are presented in brief [1-4]:

$1.1 .0 \leq C_{1}(\underline{\mathrm{x}}) \leq 10.0$ : where $C_{1}(\underline{\mathrm{x}})$ ensures that pump's available horsepower should be more than the horsepower required for the job as high hydraulic power is required for injection. Figure 5 shows the schematic of P-3D fracture geometry.

$2.1 .0 \leq C_{3}(\underline{\mathrm{x}}) \leq 15$ : where $C_{3}(\underline{\mathrm{x}})$ ensures that design pressure rating of all surface and downhole equipment are more than the pressure developed during the injection.

$3.1 .0 \leq C_{4}(\underline{\mathrm{x}}) \leq 10.0$ : where $C_{4}(\underline{\mathrm{x}})$ means the limitation of fracture height to migrate to bounding layers, avoiding interacting any undesirable formations.

4.1.0 $\leq C_{6}(\underline{\mathrm{x}}) \leq 5.0$ : where $C_{6}(\underline{\mathrm{x}})$ means the average dynamic fracture width being minimum four times the proppant diameter. This makes proppant transportation to the end of the fracture as much as possible.

5.1.0 $\leq C_{8}(\underline{\mathrm{x}}) \leq 10.0$ : where $C_{8}(\underline{\mathrm{x}})$ means that the formation critical pressure must be greater than the fracture treatment pressure for proper fracture growth with containment.

$6.1 .0 \leq C_{9}(\underline{\mathrm{x}}) \leq 10.0$ : where $C_{9}(\underline{\mathrm{x}})$ means the net fracture pressure (at the bottom hole) not exceeding the difference between the minimum horizontal stresses of the target formation and the upper and lower bound layers to contain the fracture.

\section{DESIGN OBJECTIVE}

Any optimization algorithm needs an objective function. Algorithm can demonstrate its capability to generate a compromised design by resolving conflicts when there are two measures of merit. The general form of the objective function is $[1,10]$ :

$$
\text { minimize } Z=\sum_{i=1}^{I} \frac{\left(f_{i}(\underline{x})-T_{i}\right)}{D_{i}} P_{i}
$$

where $f_{i}(\underline{x})$ is the objective function for $i$-th objective; $T_{i}$ is the target value for the $i$-th objective; $D_{i}$ is the dividing factor for $i$-th objective equation and $P_{i}$ is the priority to achieve the $i$-th objective (if there is a requirement). $I$ is the total number of measures of merit in design optimization program. This algorithm can handle combined objective functions.

- Maximize total gas production $\left(G_{p}\right)$ over a number of years.

$$
\text { minimize } Z=\text { minimize }\left(-G_{p}\right)
$$

- Maximize net present value (NPV) over a number of years.

$$
\text { minimize } Z=\text { minimize }(-N P V)
$$

\section{APPLICATION TO UNCONVENTIONAL GAS RESOURCES}

All the modules in Figure 1 are defined with data, mathematics and logics, where applicable. A computer was written in FORTRAN90. Modules are linked to the optimization algorithm. Design requirements, fracture geometry, gas production and economics are defined mathematically and are also linked to objective function. Table 2 shows the data for tight gas formation.

Table 3 shows the data for ultra-tight shale gas formation (to be stimulated by transversely fractured horizontal well, Figure 7). Transversely fractured horizontal well in 
ultra-tight shale gas formation is considered to be stimulated here. For optimum design, in addition to this integrated model, simulators (provided by Schlumberger) has been utilized. These simulators are apt in modeling of reservoirs that produces relatively dry gas, with minimal interference from other liquids such as oil or water with their own set of advantages and disadvantages. A discrete natural fracture network (DFN) is incorporated in the geometry. Properties of discrete features are also the component controlling flow and transport. DFN can lead to a more realistic description of the network as they are stochastic models that incorporate statistical scaling rules derived from analysis of fracture length, fracture height, spacing between two fractures, fracture orientation and direction, and fracture aperture [26-28].

\section{RESULTS AND DISCUSSIONS}

Three arbitrarily different designs are applied to the model as initial design to run the program to achieve the maximum NPV from a fractured vertical well in tight gas formation (Table 2). The program runs for a number of iterations for each arbitrary initial design until the optimization model was successfully able to achieve the final optimum design. Three optimum designs, starting with three arbitrary initial designs, were found with slight different values within the tolerance of convergence (not presented here). Results of one such initial design and the optimum design are presented in Table 4 [4]. Initial designs are enhanced drastically by maximum $44 \%$ in NPV. This is the improvement as well as the benefit of using this integrated hydraulic fracturing optimization model. This optimization model will greatly increase the performance of a hydraulic fracture engineer to achieve the best possible design, which can be executed in the field, satisfying all design requirements [29].

The program was run for both objectives (Design One1: maximization of total gas production and Design Two: maximization of net present value) for about 10 years production. The program was also run for the third objective (Design Three: maximizing NPV and minimizing treatment cost, $\mathrm{C}_{\mathrm{tr}}$ ). Results of three design objectives are presented in Table 4. The maximum NPV design (Design Two) is similar to the maximum production design (Design One). In Design Three, optimum design is different and a substantial treatment cost savings of $45 \%$ (over 10 years) have been achieved over Design One and Design Two. However, this saving is as a result of $11 \%$ NPV reduction over 10 years. This is a compromised design, as handled by this optimization algorithm, by adjusting priority factors to individual measures of merit. Though this objective is not so important to the petroleum industry, authors did this work to present the capability of this algorithm. The gas production model was run for the same well with no hydraulic fracture. It is evident that there was significant incremental production of gas (by about 300\%) compared to non-fractured well, presented in Figure 6, which shows the production profile for ten years [30]. Predicted cumulative gas production from non-fractured vertical well over ten years is $6 \mathrm{BSCF}$ and the same for the fractured well is $26 \mathrm{BSCF}$ for 640 acres

With regard to ultra-tight shale gas stimulation, different stages are involved using the simulators (not detailed here). reservoir.

After building and validating the models using industrial static simulators, a simplistic model was constructed to study the benefit of hydraulic fracturing. As shown in Figure 7, the simplistic model integrates a horizontal well with ten transverse hydraulic fractures and two sets of natural fractures in a shale gas formation. The interaction between natural fractures and hydraulic fractures, the pressure response and the cumulative gas production with regard to changes in fracture properties are studied and investigated. The study is extended by building a realistic model based on Marcellus Shale data along with field parameters as shown in Figure 8. Based on 10 transverse fractures (ten stages) in this horizontal well, shale gas production rate and cumulative production are presented for ten years (Figure 9) from 120 acres reservoir. This is the predicted benefit of hydraulic fracturing. Without fracturing, there is no gas flow because of ultra-tight shale formation (nano-Darcy permeability formation). So, hydraulic fracturing is a must for exploiting unconventional gas resources.

\section{CONCLUSIONS}

Based on this study, the following conclusions are made:

- The proposed optimization model with direct search based Genetic \& Polytope algorithm can deal with non-linearity, non-differentiability and discontinuity and optimize hydraulic fracture treatment design parameters, satisfying all design constraints. Algorithm can handle two measures of merit.

- Maximum gas production can be achieved from tight and ultra-tight formations by implementing this optimum design, which should be executable as design constraints are satisfied. Any arbitrary design may or may not be executable, but the optimum design gives the maximum benefit in terms of maximum production and maximum NPV. Predicted gas production is much higher compared to a non-fractured well.

- Based on a comprehensive simulation study (using industrial simulators) on ultra-tight shale gas formation, a set of transverse fractures can be designed for a horizontal well and gas production can be predicted if optimum design is properly executed in the field. It is evident that there is no gas flow through the unconventional shale gas formation without hydraulic fracturing. With fracturing, there is significant gas production predicted for ten years (5 BSCF) compared to no-flow from non-fractured well.

- With this simulation and modeling, propagation of hydraulic fracture and it's interaction with natural fractures in shale gas formations can be predicted and effect of treatment design parameters on gas production can also be conducted using a sensitivity analysis (not presented here).

\section{ACKNOWLEDGMENT}

Authors express their sincerest gratitude to Khalifa University of Science and Technology for providing opportunities in conducting this study. Authors would also like to extend their thanks to National Energy Technology Laboratory and Schlumberger, for their software donation to 

OF DIRECT SEARCH BASED OPTIMIZATION ALGORITHM

Khalifa University and for graciously allowing to utilize their software for this investigation.

\section{REFERENCES}

1. M.M. Rahman, M.K., Rahman, S.S. Rahman, "An Integrated Model for Multi-objective Design Optimization of Hydraulic Fracturing", J. of Petroleum Science and Engineering, 2001, 31, pp. 41-62.

2. M.M. Rahman, M.K. Rahman, S.S. Rahman, "Multivariate Fracture Treatment Optimization for Enhanced Gas Production from Tight Reservoirs", SPE 75702, Gas Technology Symposium, Calgary, Alberta, Canada, April 30-May 2, 2002.

3. M.M. Rahman, "Constrained Hydraulic Fracture Optimization Improves Low Permeable Oil Reservoirs", Energy Sources, Part A, 2008, 30, pp. 536-551.

4. M.M. Rahman, "Hydraulic Fracture Optimization Model with Intelligent Moving Object Algorithm to Maximize Gas production in Petroleum Industry", An International Conference on Engineering and Applied Sciences Optimization, OPT-I, Kos Island, Greece, 4-6 June, 2014.

5. B.D. Bunday. Basic Optimization Methods. Edward Arnold Ltd., London, 1984.

6. J. N. Ogbechie, "Fracture Modeling and Flow Behavior in Shale Gas Reservoirs Using Discrete Fracture Networks", MSc Thesis, Texas A\&M University, 2011.

7. A. L. Khlaifat, H. Qutob, N. Barakat, "Tight Gas Sands Development Is Critical To Future World Energy Resources", SPE-142049 Middle East Unconventional Gas Conference and Exhibition, Muscat, Oman, 2011.

8. P. Valko, M.J. Economides, "Hydraulic Fracture Mechanics", John Wiley and Sons, Chichester, England, 1995.

9. M.M. Rahman, M.K. Rahman, S.S. Rahman, "Optimizing Treatment Parameters for Enhanced Hydrocarbon Production by Hydraulic Fracturing", J. of Canadian Petroleum Technology, vol. 32 (6), pp. 38-46, 2003.

10. M.K. Rahman, "An intelligent moving object optimization algorithm for design problems with mixed variables, mixed constraints and multiple objectives", Structural and Multidisciplinary Optimization, 32, pp. 40-58, 2006.

11. B.T. Polyak, "Introduction to Optimization", Optimization Software Inc., New York, 1987.

12. J.P. Ignizio, "Linear Programming in Single and Multiple-objective Systems", Prentice- Hall Inc., Englewood Cliffs, New Jersey, 1982.

13. J.G. Ndiritu, T.M. Daniell, "An improved genetic algorithm for continuous and mixed discrete-continuous optimization", Engineering Optimization, 31, pp. 589-614, 1999.

14. J.A. Nelder, R. Mead, "A simplex method for function minimization”, Computer Journal, 7, pp. 308-313, 1965.

15. J.L. Marcelin, "Evolutionary optimization of mechanical structures", Engineering Optimization, 31, 571-588, 1999.

16. T.K. Parkins, L.R. Kern, "Widths of hydraulic fractures", J. of Petroleum Technology, September, pp. 937-949, 1961.

17. R.P. Nordgren, "Propagation of a vertical hydraulic fracture", Society of Petroleum Engineers J., August, pp. 306-314, 1972.

18. G.C. Howard, C.R. Fast, "Optimum fluid characteristics for fracture extension", Drilling and Production Practices, API (Appendix by E.D. Carter: derivation of the general equation for estimating the extent of the fractured area), pp. 261-270, 1957

19. M.M Rahman, M.K. Rahman, S.S. Rahman, "Multicriteria Hydraulic Fracturing Optimization for Reservoir Stimulation", Petroleum Science and Technology, 2003, 21 (11-12), pp. 1721-1758.

20. N. R. Warpinski and M.B. Smith, "Rock Mechanics and fracture geometry", In: Recent Advances in Hydraulic Fracturing, Monograph Vol. 2, Gidley, J.L. et al. (Eds.). Richardson, TX : SPE, 1989.

21. Y. Gao, "Modeling of Transient Pressure Behaviors for Transversely Fractured Horizontal Well in Naturally Fractured Reservoir", M.Sc. Thesis, Khalifa University of Science and Technology, 2018.

22. D. Biswas, "Shale Gas Predictive Model (SGPM) - An Alternate approach to predict shale gas production", SPE 148491 Eastern Regional Meeting, Columbus, Ohio, USA, 17-19 August, 2011.

23. N. Li, Q. Ran, J. Li, J. Yuan, C. Wang, Y. Wu, "A Multiple-Continuum Model for Simulation of Gas production from Shale Gas Reservoirs", SPE 165991 Reservoir Characterisation and Simulation Conference and Exhibition, Abu Dhabi, UAE, 16-18 September, 2013.

24. O.A. Adefidipe, H. Dehghanpour, C.J. Virues, "Immediate gas production from shale gas Wells: A Two-phase Flowback Model”, SPE 168982 Unconventional Resources Conference, The Woodlands, TX, USA, 1-3 April,2014.

25. F. Wang, Z. Pan, Y. Zhang, S. Zhang, "Simulation of coupled hydro-mechanical-chemical phenomena in hydraulically fractured gas shale during fracturing-fluid flowback", J. of Petroleum Science and Engineering, vol. 163, April 2018, pp.16-26.

26. J. C. Pashin, G. Jin, C. Zheng, S. Chen,M. R. McIntyre, "Discrete Fracture Network Models of the Secarb Carbon Sequestration Test Site, Deerlick Creek Field, Black Warrior Basin, Alabama". Paper 0821, International Coalbed \& Shale Gas Symposium, Tuscaloosa, Alabama, 2008.

27. A. Suboyin, "Hydraulic Fracture Propagation in the Presence of Natural Fractures in Shale Gas Reservoirs", M.Sc. Thesis, Khalifa University of Science and Technology, 2018.

28. A. Suboyin, M.M. Rahman, M. Haroun, A. Shaik, "A Novel Dynamic Assessment of Multi-Stage Hydraulic Fracture Propagation in Presence of Natural Fractures in Shale Gas Reservoirs", SPE192811 Abu Dhabi International Petroleum Exhibition and Conference, 12-15 November, Abu Dhabi, UAE, 2018.

29. M.M Rahman, M.K. Rahman, "Optimizing Hydraulic Fracture to Manage Sand Production by Predicting Critical Drawdown Pressure in Gas Well", J. of Energy Resources Technology, 2012, 134, pp. 013101-1 013101-9.

30. M.M. Rahman, H.K. Sarma, "Maximizing Tight Gas Recovery through a New Hydraulic Fracture Optimization Model", SPE 148205, Reservoir Characterization and Simulation Conf. and Exh., Abu Dhabi, 9-11 October 2011. 
Table 1. Free design variables and their bound values

\begin{tabular}{|c|c|c|}
\hline Variable name (unit) & $\begin{array}{c}\text { Variable } \\
\text { symbol }\end{array}$ & Bound values \\
\hline Injection rate (bbl/min) & $q_{i}$ & $10-40$ \\
\hline $\begin{array}{c}\text { Injection time (min) } \\
\text { (ppg) }\end{array}$ & $t_{i}$ & $30-200$ \\
\hline $\begin{array}{c}\text { End of the Job Proppant concentration } \\
\text { Fracturing fluid viscosity (cp) }\end{array}$ & $\mu$ & 15 \\
\hline
\end{tabular}

Table 2. Tight Gas formation, geomechanical and wellbore data $[1,4]$

\begin{tabular}{|c|c|}
\hline Parameters & Value \\
\hline Drainage area (square shape) & 640 acres \\
\hline Average depth & $7,500 \mathrm{ft}$ \\
\hline Thickness & $100 \mathrm{ft}$ \\
\hline Porosity & $10 \%$ \\
\hline Permeability & $0.20 \mathrm{md}$ \\
\hline Reservoir pressure $\&$ temperature & 4,400 psi, $200 \mathrm{~F}$ \\
\hline Gas saturation & 0.8 \\
\hline Water compressibility & $3.0 \mathrm{E}-6 \mathrm{psi}^{-1}$ \\
\hline Pore compressibility & $8.6 \mathrm{E}-6 \mathrm{psi}^{-1}$ \\
\hline Max. horizontal stress & $7,000 \mathrm{psi}$ \\
\hline Min. horizontal stress (closure stress) & $6,000 \mathrm{psi}$ \\
\hline Min. horizontal stress (shale) & $6.700 \mathrm{psi}$ \\
\hline Young's modulus & $5.075 \mathrm{E}-6$ \\
\hline Poisson's ratio & 0.20 \\
\hline Leakoff coefficient & $0.00025 \mathrm{ft} / \mathrm{min}^{0.5}$ \\
\hline Wellbore radius & $0.35 \mathrm{ft}$ \\
\hline Flowing bottomhole pressure & $1,700 \mathrm{psi}$ \\
\hline Tubing inside diameter & 2.992 inch \\
\hline Rated pressure for surface equipment & $14,000 \mathrm{psi}$ \\
\hline
\end{tabular}

Table 3. Ultra-tight Shale Gas formation and Geomechanical data [27, 28]

\begin{tabular}{|c|c|}
\hline Parameters & Value \\
\hline Drainage area (square shape) & $120 \mathrm{acres}$ \\
\hline Average depth & $11,000 \mathrm{ft}$ \\
\hline Thickness & $283 \mathrm{ft}$ \\
\hline Porosity & $4 \%$ \\
\hline Permeability & 0.5 micro-Darcy \\
\hline Reservoir pressure \& temperature & $7,000 \mathrm{psi}, 285 \mathrm{~F}$ \\
\hline
\end{tabular}



OF DIRECT SEARCH BASED OPTIMIZATION ALGORITHM

\begin{tabular}{|c|c|}
\hline Wellbore Lateral length & $3700 \mathrm{ft}$ \\
\hline Number of fracture stages & $100 \mathrm{ft}$ \\
\hline Fracture spacing & 0.8 and 0.621 \\
\hline Gas saturation and specific gravity & $0.02 \mathrm{cp}$ \\
\hline Reservoir gas viscosity & $65 \mathrm{MPa}$ \\
\hline Vertical stress & $45 \mathrm{MPa}$ \\
\hline Max. horizontal stress & $35 \mathrm{MPa}$ \\
\hline Min. horizontal stress & $30 \mathrm{GPa}$ \\
\hline Young's modulus & 0.20 \\
\hline Poisson's ratio & $4 \mathrm{MPa}$ \\
\hline Tensile strength & $33 / \mathrm{GPa}$ \\
\hline Rock compressibility & $3,600 \mathrm{psi}$ \\
\hline Flowing bottomhole pressure & \\
\hline
\end{tabular}

Table 4. Initial Design and Optimum design for three different objective functions [1,4]

\begin{tabular}{|c|c|c|c|c|}
\hline Variable symbol & $\begin{array}{c}\text { Arbitrary } \\
\text { Initial } \\
\text { Design }\end{array}$ & Design One & Design Two & $\begin{array}{c}\text { Design } \\
\text { Three }\end{array}$ \\
\hline$q_{i}(\mathrm{bbl} / \mathrm{min})$ & 30 & 24 & 24 & 15 \\
\hline$t_{i}(\mathrm{~min})$ & 67 & 134 & 134 & 82.5 \\
\hline$P_{c}(\mathrm{ppg})$ & 7 & 15 & 15 & 14.5 \\
\hline$\mu(\mathrm{cp})$ & 210 & 99.7 & 99.8 & 89.3 \\
\hline$x_{f}(\mathrm{ft})$ & 550 & 2,500 & 2,498 & 1,581 \\
\hline $\mathrm{NPV}(\mathrm{m} \$)$ & 11.423 & 16.530 & 16.528 & 14.749 \\
\hline $\mathrm{G}_{\mathrm{p}}(\mathrm{bscf})$ & 18.357 & 26.294 & 26.291 & 23.110 \\
\hline $\mathrm{C}_{\mathrm{tr}}(\mathrm{m} \$)$ & 0.5757 & 1.000 & 0.998 & 0.551 \\
\hline
\end{tabular}




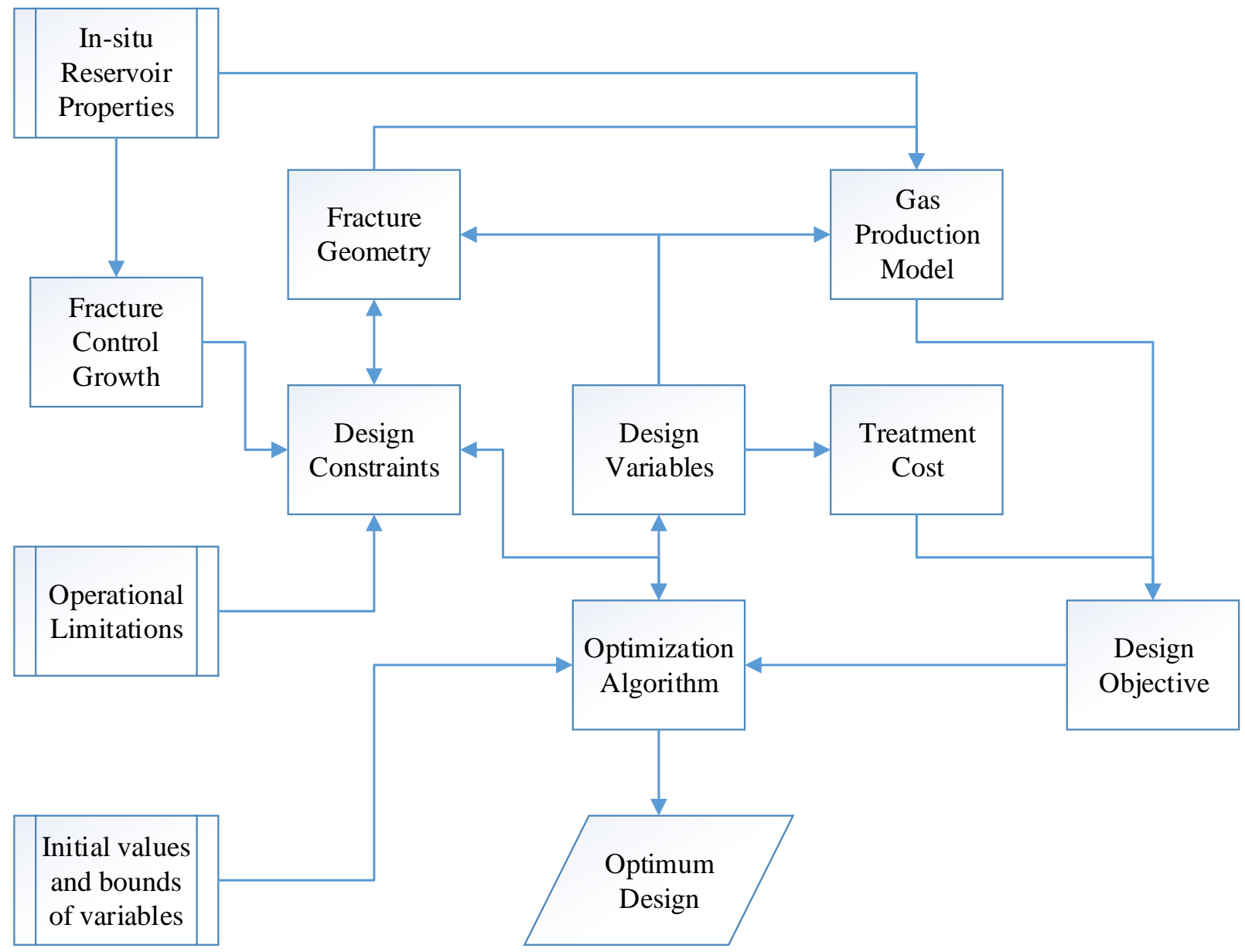

Figure 1. Hydraulic fracturing design

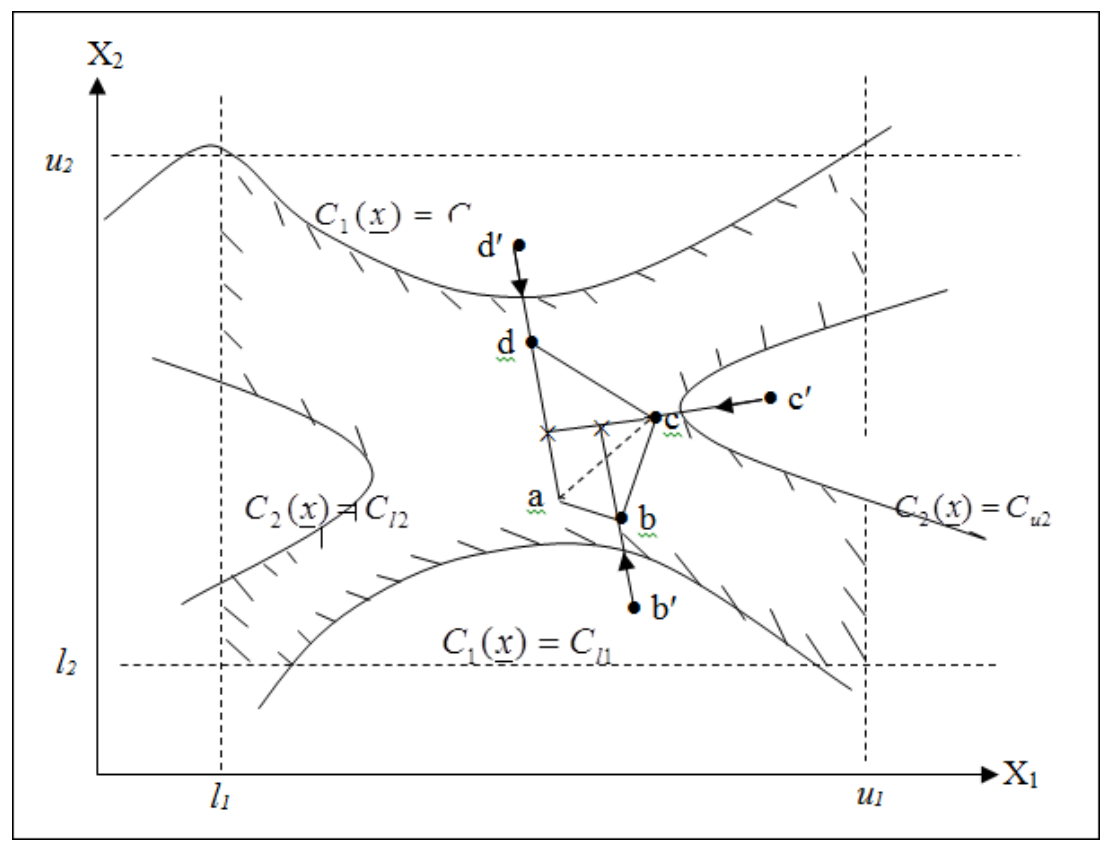

Figure 2. A compound with four vertices [4] 


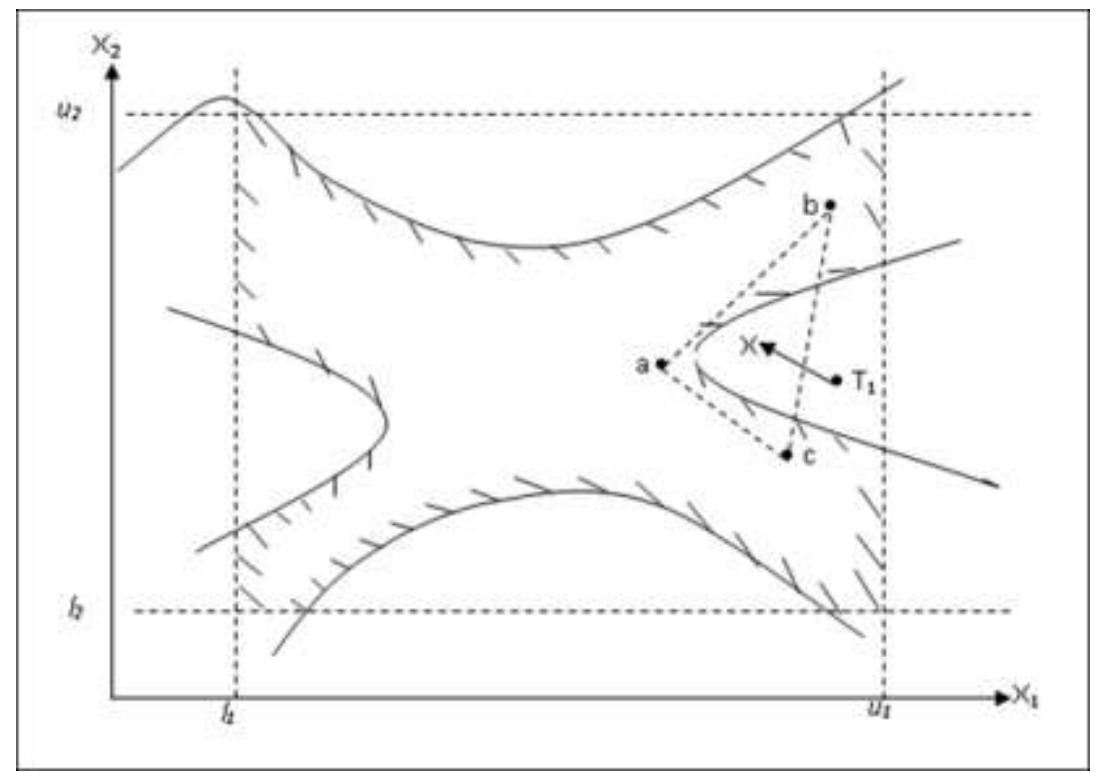

Figure 3. A compound with three vertices 'a, b, c' [4]

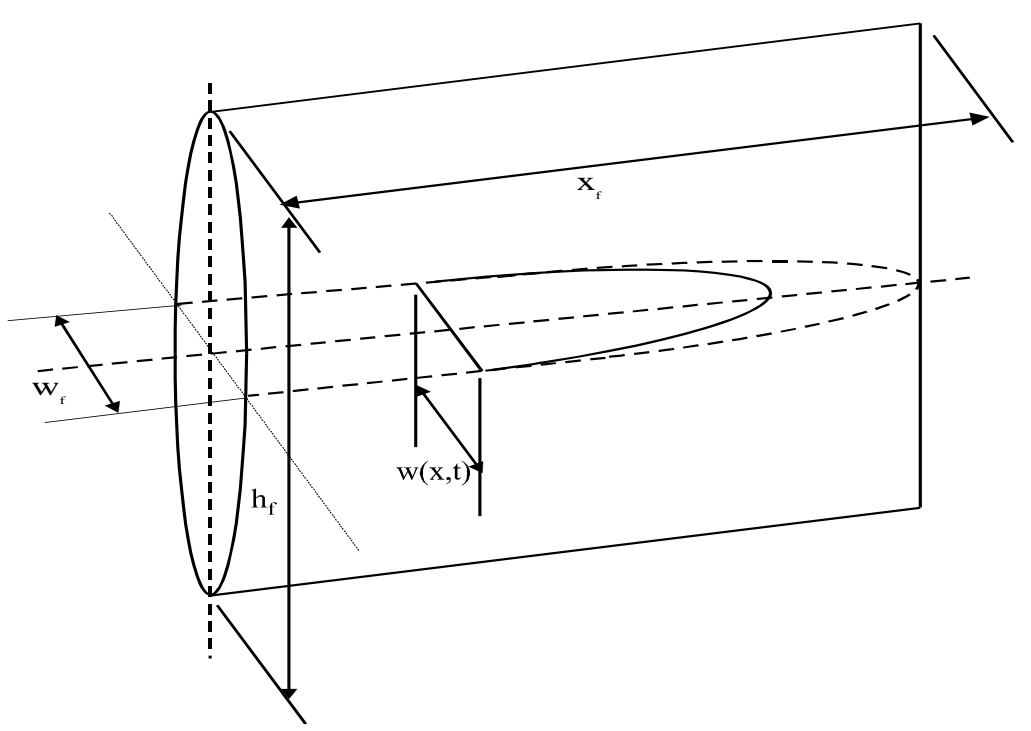

Figure 4. 2D PKN fracture model $[16,17]$

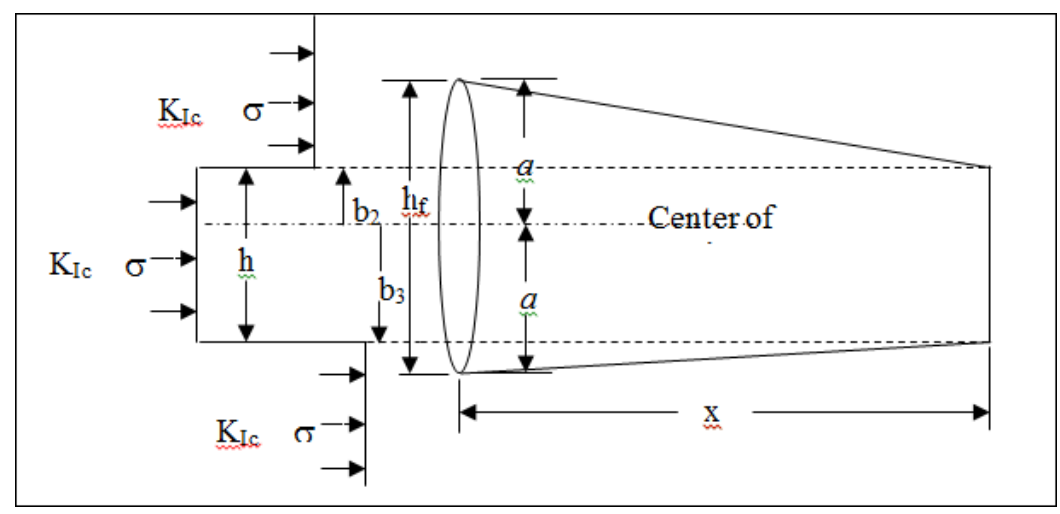

Figure 5. Three layered stress medium and P-3D Fracture Model [19,20] 


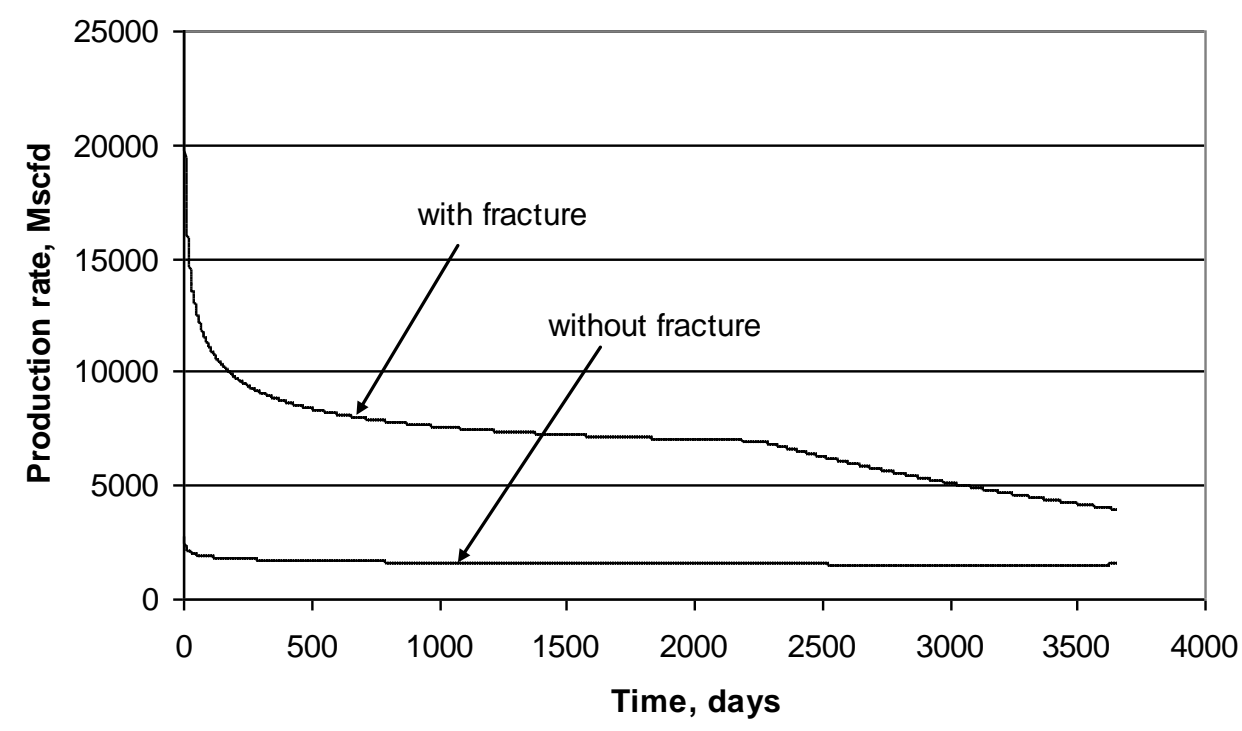

Figure 6. Prediction of gas production profile for ten years

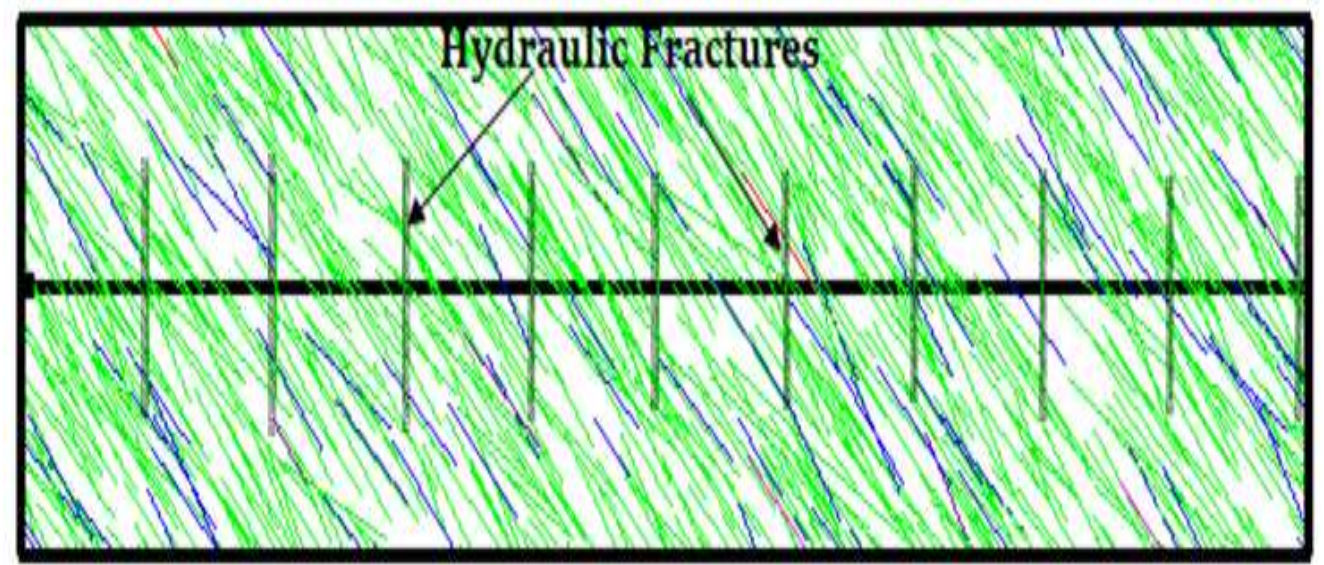

Figure 7. A horizontal well fractured transversely in 10 stages: a simplistic model [27, 28]

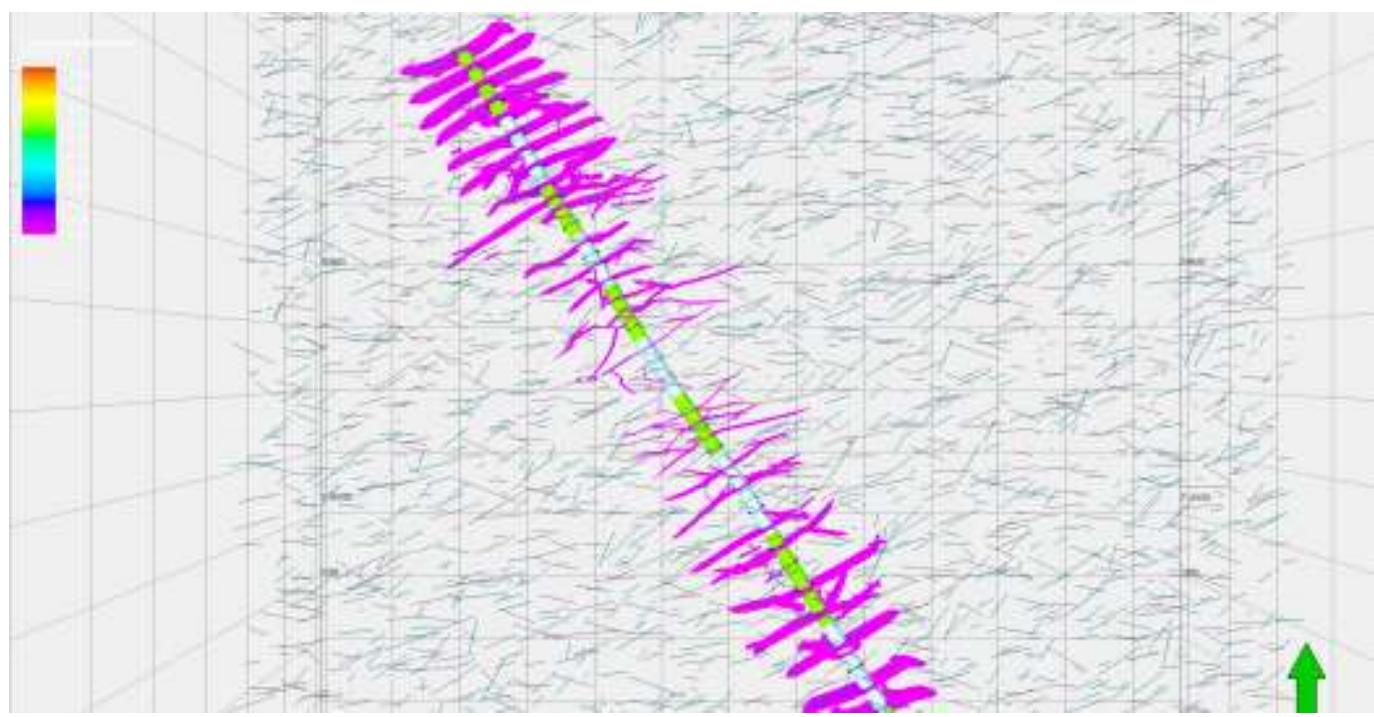

Figure 8. Simplistic representation of constructed realistic model $[27,28]$

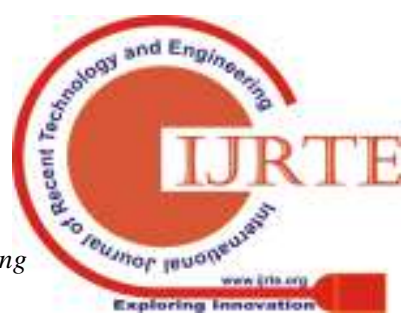



OF DIRECT SEARCH BASED OPTIMIZATION ALGORITHM

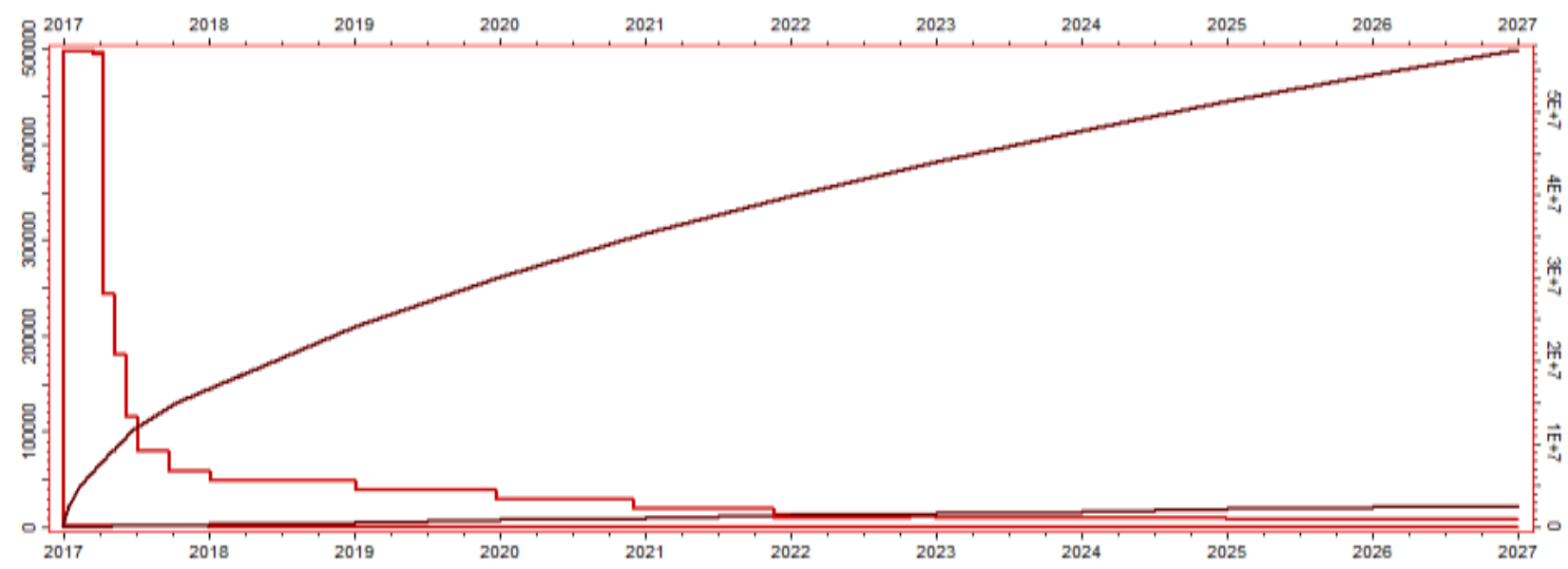

\begin{tabular}{|c|c|c|}
\cline { 2 - 3 } \multicolumn{1}{c|}{} & Daily (Initial) & Cumulative \\
\hline With Fractures & 5 MMSCF/Day & 5 BSCF \\
\hline Without Fractures & $\sim 0$ & $\sim$ Less than 0.05\% \\
\hline
\end{tabular}

Figure 9. Fracture versus No fracture - Shale gas production 